Revista Iberoamericana, Vol. LXXX, Núm. 246, Enero-Marzo 2014, 31-48

\title{
REVISIÓN, ADAPTACIÓN Y TRADUCCIÓN: EDITAR EL TEXTO FLUIDO EN LA ERA DIGITAL
}

\author{
POR \\ JOHN BRYANT \\ Hofstra University
}

La edición académica es una empresa de la crítica, pero es muy difícil de reconocer, dado el reducido lugar que los estudios textuales ocupan en nuestra profesión. La opinión general es que los editores limpian las llamadas corrupciones textuales que subrepticiamente se cuelan en una obra literaria con el paso del tiempo y que generan las ediciones supuestamente "definitivas” para que los críticos literarios las interpreten. O así es como se supone que funciona. Así, la categoría profesional conocida como "crítica textual” -que incluía el tipo de pensamiento crítico en el que se basaba la creación de "ediciones críticas"- despierta hoy en día opiniones extrañas y, más a menudo, es mal encarada. Si se le pregunta a los colegas o a los estudiantes graduados qué es la "crítica textual”, la mayoría nos preguntarían, a su vez, “¿Qué crítica?”.

Por supuesto, aquellos de nosotros que desarrollamos “crítica genética” es probable que encontremos esta respuesta ligeramente exasperante. Si ustedes han venido aquí a compartir sus hallazgos críticos en el estudio de manuscritos, sus interpretaciones de los bocetos, borradores y esbozos de un autor o las palabras rechazadas de otro, o sus reflexiones sobre la escritura de otro: en resumen, si uno es un genetista, sabe que el tipo de lectura que llevamos adelante -la lectura de un texto a medida que evolucionaes necesariamente un esfuerzo crítico, que establecer el texto de un texto en evolución o texto fluido requiere una buena dosis de interpretación y que la edición de un texto genético es, inevitablemente, un acto de interpretación.

En el estudio del borrador de trabajo de Typee de Mellville, un manuscrito fragmentario que consta de tres capítulos, he descubierto la evidencia de tres modos de revisión distintos, aunque hipotéticos. Comencé con la edición del documento, simplemente para hacer legible la ubicación de las revisiones. Pero, de hecho, sólo a través de la edición fui capaz de comprender las tres etapas de revisión que se superponían en el documento. También me di cuenta de que lo que estaba leyendo no era un texto fijo sino más bien un texto fluido, uno que había evolucionado a través de múltiples versiones secuenciales. El proceso creativo de Melville y sus cambiantes intenciones parecían disponerse ante mí. Pero todavía no podía "ver” o verdaderamente presenciar todos esos 
muchos lugares de recisión hasta que indagué por el significado de cada revisión: cada cancelación, falso comienzo e inserción, sobre la línea, debajo, en el margen. Descubrí que mientras Melville escribía su primer borrador, recordaba muchas de sus aventuras personales en las que se basaba su libro y que, en su transformación de sus experiencias en narración, también se transformaba a sí mismo políticamente, y lo hacía con enfado.

Pero hay más: he descubierto que lo que parecía un simple acto de determinar que una marca en la página era, de hecho, una revisión, ese acto mismo requería actos de interpretación. Un día, un garabato, que previamente había transcripto como un mero garabato, de repente se me apareció como un pronombre interrogativo a medio escribir ("wh”). Ya no era más un garabato, ahora era un falso comienzo de la palabra "which”, lo que me indicó que Melville, durante el acto de composición, había considerado inicialmente reconsiderándo inmediatamente, escribir una cláusula con "which", que podía conectar con otra cláusula de "which” más abajo en la página, todo lo cual indicaba una reelaboración de parte de Melville, no sólo al nivel de la estructura de la oración sino también de su contenido político y su estrategia retórica. Previamente, la "wh" semi escrita no era más que un garabato, ahora era una revisión, pero no había sido capaz de ver el garabato como una revisión hasta que encontré un significado que atribuirle en el contexto de la subsecuente escritura de Melvile en la página manuscrita. Lo que quiero decir es que para determinar si una inscripción es una revisión o no lo es, debemos interpretar primero la inscripción; por lo tanto, la revisión editorial es, en lo fundamental, un acto interpretativo.

Dar una interpretación política a los actos de la memoria y de la escritura, basándose en un garabato a medio escribir: Esto no es "objetivo"; esto no es "científico". ¿No es esto subjetivo y, por lo tanto, vergonzante? Sí, pero no. Editar cualquier obra es necesariamente un esfuerzo crítico y por ende, propenso a la subjetividad. La revisión editorial es, por las mencionadas razones, involucrar más niveles de juicio crítico. Pero la respuesta de los "textual scholars" a esta subjetividad condicionada a la hora de editar es proveer a los lectores de los argumentos que apoyan los juicios que dan forma a la edición. En consecuencia, toda la edición académica es edición crítica. Así que antes que negar que nuestras ediciones son actos interpretativos, quiero sostener la perspectiva de que editar es, ineluctablemente, una forma de pensamiento crítico y de crítica en sí. El problema entonces no es cómo evitar la subjetividad a la hora de editar sino cómo exponerla, involucrando a los lectores por completo en el proceso de la edición crítica. Y, al mismo tiempo, hay que entender la genética en tanto campo interpretativo y también como un modo de edición textual. Quiero entonces subrayar algunos fundamentos de lo que yo llamo la edición del texto fluido y sus intersecciones con la crítica genética. De este modo, quiero tratar la ética de la edición, la participación de la adaptación y la traducción y las formas en las que la tecnología digital mejorará la edición y el estudio del proceso genético.

\footnotetext{
Revista Iberoamericana, Vol. LXXX, Núm. 246, Enero-Marzo 2014, $31-48$
ISSN 0034-9631 (Impreso)
} 
Quiero comenzar con algunos fundamentos. La edición crítica se enfrenta con al menos tres problemas: la textualidad, la intencionalidad y el "empoderamiento" del lector. La edición académica en la tradición de Greg-Bowers-Tanselle es famosa por valorizar las intenciones finales del autor, esto es, el estado del texto tal y como abandona la mano del autor y antes de que llegue al editor o impresor. Aquí, la textualidad está representada por un momento idealizado de autoría libre del peso de las presiones del mercado (Tanselle; ver también Greetham). La edición colectiva de textos, tal y como la promueven D. F. McKenzie, Jerome J. McGann $(1983,1991)$ y otros, extiende la noción de textualidad hasta incluir apariciones pre y pos publicación del texto y cómo esos entornos biobibliográficos modulan el significado. Aquí, la intencionalidad se extiende para incluir la colaboración no autoral. La crítica genética francesa y alemana -ejemplificada en el trabajo hecho en el Institut des Textes et Manuscrits Modernes (ITEM) y en el trabajo de Hans Walter Gabler-se concentra en el avant-texte y el proceso de la escritura generalmente antes del momento de la publicación. Aquí, la textualidad se entiende como concretamente determinada por la colocación del documento y la intencionalidad es casi exclusivamente autoral pero siempre cambiante, nunca realmente "final” (Gabler, Bornstein y Pierce).

Mientras que estos tres enfoques editoriales difieren en términos de textualidad e intencionalidad, comparten los mismos objetivos para empoderar al lector. Esto significa que las ediciones críticas incluyen un aparato que provee a los lectores de información -aunque a menudo muy codificada, información casi indescifrable-para reconstruir las versiones de un trabajo y mostrar las enmiendas y los cambios en el texto de los editores.

El enfoque editorial del texto fluido comprende estas tres etapas pero también las extiende. Un texto fluido es cualquier obra escrita que existe en múltiples versiones. Una versión es cualquier texto cuya identidad se conecta con, pero es significativamente diferente de, una obra que le da origen (originating work). Los límites de una identidad textual pueden determinarse por la intervención de un autor que le da origen o por otras manos, en otros momentos, con intenciones variantes, y para diferentes propósitos retóricos. Tomemos Typee de Melville, por ejemplo.

Como ya se ha dicho, una considerable sección del primer borrador de Typee de Melville existe en manuscrito. Melville convirtió su borrador de trabajo en una copia en limpio, que se ha perdido, y cuando se compuso tipográficamente, agregó capítulos y otras revisiones (Bryant, Melville Unfolding). Sin embargo, las pruebas de página de Typee también se han perdido. John Murray publicó el libro por primera vez en el Reino Unido en febrero de 1846 y esa versión es significativamente diferente del texto final que aparece en el manuscrito. Un mes más tarde, Typee se re-estableció para la edición estadounidense, publicada por John Wiley, con cambios menores. Pero en ese

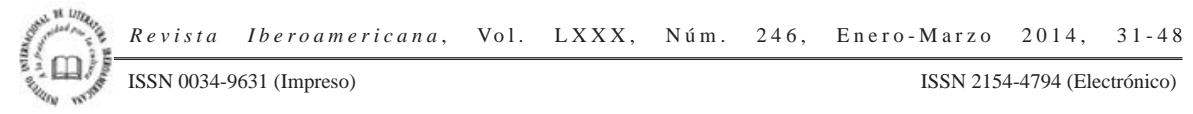


verano, las reseñas críticas de la prensa religiosa obligaron a Melville a expurgar casi el quince por ciento del libro para una edición estadounidense revisada. Al mismo tiempo, expandió el libro agregándole “The Story of Toby”, una breve narración de la huida de su compañero Tobias Greene. Otra vez en Inglaterra, Murray se negó a las expurgaciones estadounidenses de Melville, pero agregó “The Story of Toby” a las subsiguientes ediciones del texto original publicado, creando así una versión distinta de las ediciones estadounidense y estadounidense revisada, e incluso de su propia primera versión británica. De este modo, a lo largo del siglo diecinueve y buena parte del veinte, Typee circuló en dos versiones significativamente distintas en cuanto al texto de ambos lados del Atlántico: la primera versión británica aumentada para los europeos y la revisada y expurgada para los estadounidenses. Fue el único best-seller de Melville durante su vida.

Poco después del "Melville Revival” que se produjo en la década de los 20, Typee fue eclipsado en popularidad por el renovado elogio crítico que suscitó Moby Dick, pero sigue siendo sujeto de ilustración popular y adaptaciones. Fue uno de los primeros libros estadounidenses en ser incluido en la serie de historietas Classics Ilustrated. Una reciente reedición del cómic de Typee incluye información biográfica y una guía de estudio, que suena como una buena manera de arruinar un buen libro de historietas. Typee ha sido traducido a una decena de idiomas, tanto para adultos como para niños, incluyendo el griego moderno. Aunque estas adaptaciones contemporáneas son lejanas revisiones del Typee "original" de Melville, representan sin embargo las formas en las que los lectores modernos reciben el "trabajo" de Melville. A la luz del hecho de que los textos escritos evolucionan más allá del trabajo originario del autor, hay que pensar cómo podemos volver a concebir la obra literaria para que abarque la adaptación y la traducción. Y cómo, también, puede la crítica genética extenderse necesariamente más allá de la "cocina del escritor" hasta las arenas posautorales donde la obra continúa siendo revisada e incluso recreada.

Desde la perspectiva del texto fluido, la obra literaria no se restringe a un texto congelado que el autor tenía intenciones de publicar en un momento dado, a un texto genético tal como evoluciona a través de capas de revisión, ni a su representación social que varía por códigos bibliográficos (revista, libro, antología). Incluye estas modalidades autorales y editoriales pero también comprende lo que llamo "revisión cultural”, en la que los lectores revisan, adaptan y resignifican un texto en una versión materialmente alterada que, para bien o para mal, se asemeja a sus propios deseos.

El objeto de análisis del texto fluido es comprender todas las modalidades de intencionalidad, como evidentes en versiones de una obra generadas por las revisiones que no sólo hacen los autores sino que también y controvertidamente hacen, los editores y los lectores históricos que transforman la obra sin prestar atención a la intención autoral. Tal como sabemos, la génesis no es sólo un comienzo tipo Big Bang de la

Revista Iberoamericana, Vol. LXXX, Núm. 246, Enero-Marzo 2014, $31-48$
ISSN 0034-9631 (Impreso) 
composición en el escritorio de un escritor. La génesis es revisión. Un texto evoluciona a través de sucesivas rondas de revisión e incluso después de que un texto "se rinde” en lo que falsamente se asume como la forma fija y final de publicación, ese texto continúa evolucionando, tal como hemos visto con Typee, de muchas maneras. La revisión es a menudo un proceso en colaboración: familiares, secretarios, agentes, correctores, editores, incluso impresores hacen sus propias marcas en un texto fluido que evoluciona. Pero este proceso genético también continúa, con adaptadores internos al medio, tales como los escritores para niños, censores, abreviadores y traductores, así como adaptadores de otros medios como la radio, la escena, la pantalla y las bellas artes.

De este modo, una obra literaria -llámese Moby Dick- comprende la Obra total que una cultura y sus agentes ponen en los textos asociados que reinterpretan ese título. Tales versiones incluyen la concreta composición y revisiones de Melville, las alteraciones y expurgaciones que hizo el editor británico y las versiones presentadas en las ediciones académicas del siglo veinte así como las adaptaciones del siglo veinte, tales como las versiones cinematográficas muda y sonora, las dos protagonizadas por John Barrymore y la producción de John Huston con Gregory Peck, o las producciones teatrales de Orson Welles, de 1965, Moby-Dick Rehearsed y la ópera de 2011 de Jake Heggie. Estas versiones de Moby-Dick son interpretaciones críticas que se consiguen por medio de una revisión material del texto originario de Melville.

Los geneticistas pueden sentir que esta selección de adaptaciones está bien y es buena, pero ¿qué tienen que ver estas versiones, que son respuestas de lectores, con “bocetos, borradores y esbozos” o “palabras rechazadas”? ${ }^{1}$ Pensamos en el proceso de revisión del autor como un asunto privado pero un texto no existe a menos que se lo lea y un escritor moldea el lenguaje para que sea leído, por lectores. La revisión es un esfuerzo estético y social, y si bien puede que los escritores escriban en privado, revisan públicamente, con los lectores en mente. Dada esta dinámica de la revisión que incluye a los lectores futuros, podemos extender la génesis para incluir las revisiones que hacen los lectores concretos también, y por ende incluir en nuestra visión de la obra literaria llamada Moby Dick todas las versiones de Moby Dick -incluyendo sus adaptaciones y traducciones- como parte de su génesis más completa como texto fluido.

Pero ¿qué desafíos supone este enfoque del texto fluido para la crítica genética y para las ediciones genéticas? Más precisamente, llegamos a dos preguntas. La primera, ¿cuáles son las “consecuencias intepretativas” (para usar la adecuada frase de Peter Shillingsburg) de esta más concepción amplia del texto fluido de la textualidad y la intencionalidad? Y la segunda, si un texto fluido no es una Obra singularizada que se basa en un solo objeto textual sino más bien un fenómeno, tanto privado como00 cultural, que involucra múltiples identidades textuales en evolución, entonces, ¿cómo

1 Estas palabras entre comillas, en español en el original, son ecos de otros títulos del simposio. $N$. de la T.

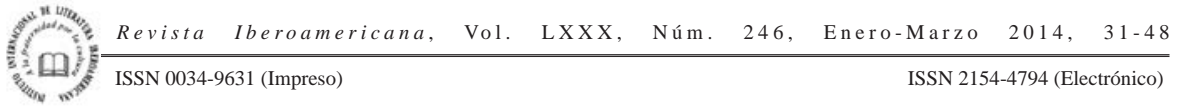


hace uno para editar un texto fluido? En síntesis, ¿cómo se edita un fenómeno? Y ¿cómo editamos éticamente para empoderar a los lectores?

La primera pregunta sobre la interpretación nos pide que consideremos qué es lo más importante e imperioso en el tratamiento de un texto fluido. Podríamos preguntarnos lo mismo acerca de la evolución en general. La revisión y las versiones son emblemas de cambio, que, tanto en un contexto privado como social, demandan interpretación. Buscamos las causas del cambio. Los textos fluidos también se nos imponen porque se hacen eco de nuestro propio deseo de evolucionar. Buscamos saber cómo cambian nuestras propias identidades, de españoles y pueblos originarios a mestizos o hispanos, a latino y latina, a quizá simplemente "yo". Al revisarnos a nosotros mismos, mezclamos identidades y cruzamos fronteras, regresamos a las raíces e inventamos nuevas identidades. La revisión textual y las identidades textuales son modelos de nuestra propia búsqueda identitaria. Tal como lo ha dicho Lawrence Venuti, la forma de revisión que llamamos traducción es, esencialmente, la "formación de identidades culturales" (67). Y, como todas las formas de revisión, la traducción está cargada de ansiedad: es inevitable, es política y es invisible. Si la ansiedad cultural está en la raíz de la revisión y es un objeto de auto interpretación crítica, entonces el texto fluido es con seguridad un objeto de interpretación y es uno que nos demanda al máximo que indaguemos cómo editar un texto fluido de manera de empoderar a los lectores.

En la medida en la que los editores establecen textos, controlan lo que los lectores consumen. Los editores tienen poder. Eligen una versión de una obra para representar todas las versiones de esa obra. Alteran su versión del texto publicado para que concuerde con su concepción de las intenciones finales del autor. Y a causa de que los editores universitarios y comerciales usan los textos de lectura de estas ediciones eruditas para reproducir la obra para una circulación más amplia, los editores tienen más poder en la producción de dar forma a las reacciones de una o dos generaciones de lectores. Se da por sentado que los editores ofrecen aparatos textuales para informar a los lectores de los cambios que introducen; sin embargo, los editores que retoman esas ediciones descartan esos apéndices cuando hacen sus propias reimpresiones. De este modo, se evita de modo sistemático que los lectores sepan más de la fluidez de una obra. El lector está esencialmente despojado de la posibilidad de una comprensión más profunda de la textualidad y la intencionalidad. El problema al editar un texto fluido, entonces, yace en cómo volver a comprometer al lector en el proceso editorial y, en realidad, en el proceso de génesis y revisión.

II

Para explorar las soluciones digitales para editar un texto fluido, quiero referirme a dos sitios editoriales en línea. El primero es mi edición electrónica de Typee, montada en línea en 2006 por la University of Virginia Press. Y el segundo es TextLab, una

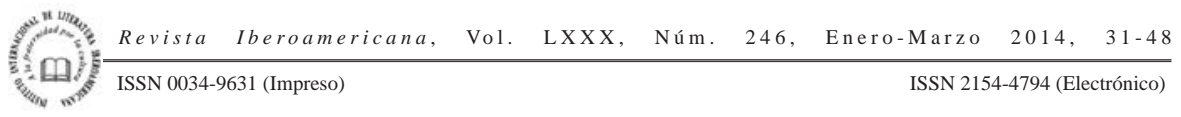


herramienta para la edición de textos fluidos en la MEL (Melville Electronic Library) que todavía está en la etapa de producción de prueba.

Para principiantes, permítanme una revisión de ejemplo del sitio en el manuscrito de Typee, que involucra una revisión típica en tres pasos. En esta escena, un isleño de Typee intenta convencer a Tommo, el protagonista de Melville, de que no debe temer al canibalismo porque el valle de Typee es tan encantador que no podría ser el hogar de caníbales (ver diapositiva 1). Al escribir esta línea por primera vez, Melville hacía que

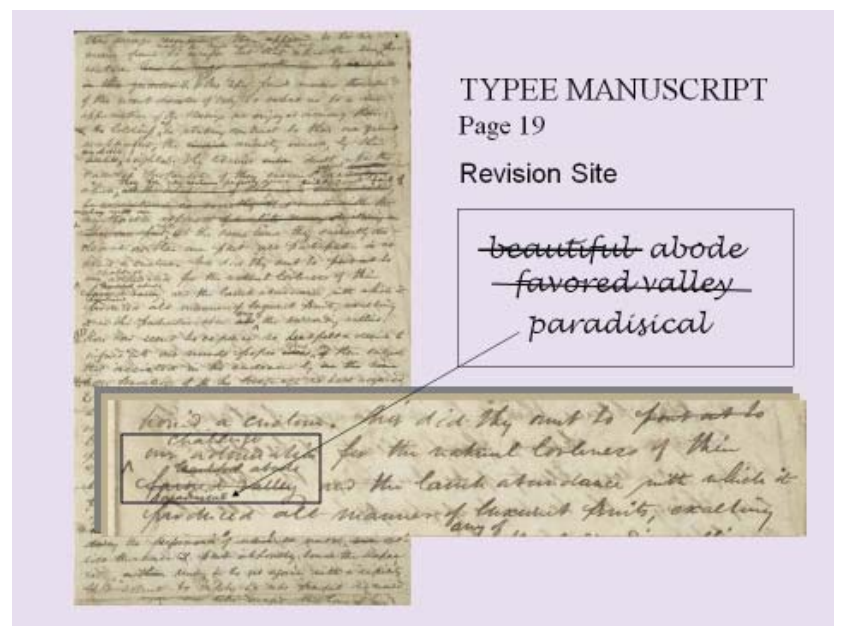

el habitante nativo dijera "su favorecido valle"/their favored valley. Un poco después, Melville cambió favored valley por "hermosa morada" (beautiful abode), que anotó directamente encima de la versión anterior. Y un poco después, borró "hermoso" e inscribió "paradisíaco" (paradisical), encima de la línea, cambiando "su bella morada" (their beautiful abode) por "su paradisíaca morada" (their paradisical abode). Sin embargo, en la primera edición impresa de Typee, nos encontramos con una revisión posterior (posiblemente hecha por el editor británico de Melville, aunque no podemos estar seguros), en la que "su paradisíaca morada" (their paradisical abode) ha sido cambiado por "su propia morada" (their own abode).

Esencialmente, los textos revisados en esta versión son invisibles. Esto es, las opciones léxicas reales en ese sitio de revisión-favored valley, beautiful abode, paradisical abode y their own abode/ "favorecido valle", "hermosa morada", "paradisíaca morada" y "su propia morada”-no están completamente inscriptas en la página del manuscrito. Sabemos, por supuesto, que cada opción existió en la cabeza de Melville mientras escribía, pero son esencialmente invisibles en la página, en la que sólo aparecen ante nosotros como

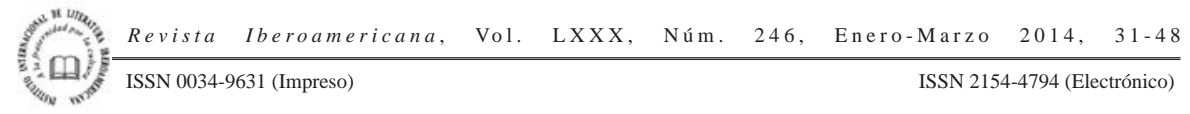


un grupo de palabras extrañamente apiladas, una especie de "código de revisión” que requiere un tipo especial de lectura para ser descifrado. Para hacer visibles los textos invisibles de la revisión, un editor debe editar los textos invisibles pero codificados de modo de hacerlos visibles, lo que significa ofrecer todas las palabras posibles que hemos decodificado. Este acto de decodificación no sólo es esencial para establecer el texto de revisión en este sitio de revisión en particular, sino que es también el primer paso que el editor de un texto fluido da hacia el empoderamiento del lector en sus intentos de presenciar el proceso de revisión de un escritor.

¿Cómo puede este proceso de decodificación traducirse a una edición de un texto fluido? Para brindar niveles crecientes de visibilidad textual, divido la edición del texto fluido de Typee en dos marcos, cada uno de ellos capaz de exhibir varios rasgos editoriales. En la diapositiva 2, una imagen digital de la hoja 19 (Leaf 19) aparece encima

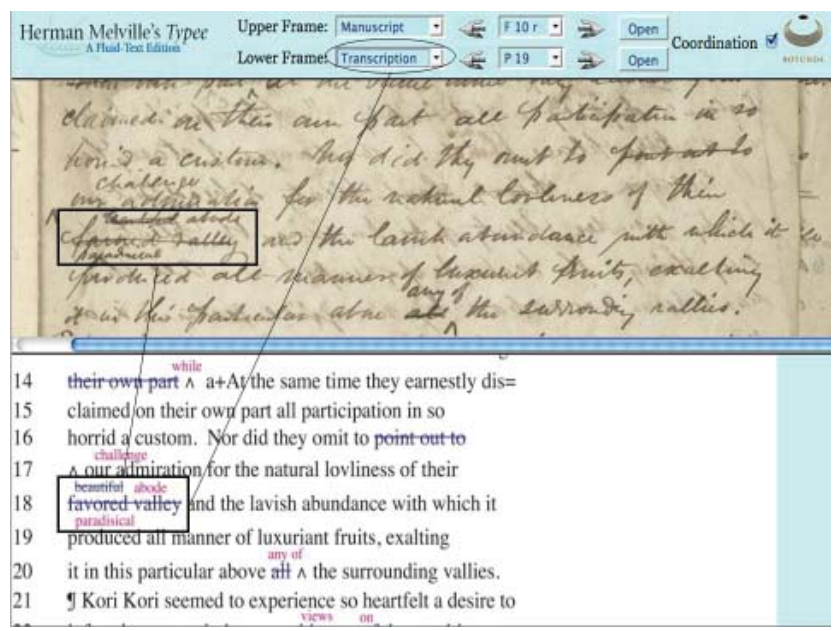

y su transcripción diplomática, que reproduce la hoja tipográficamente, aparece debajo. Aquí, se provee a los lectores de una versión legible de la hoja para que puedan leer la escritura notablemente mala de Melville. Sin embargo, la transcripción diplomática no intenta decodificar los sitios de revisión. Para hacer estos textos de revisión visibles se requieren más rasgos complejos.

Primero, el marco inferior también puede exhibir las ediciones de la "versión de base", que es la lectura final del texto del manuscrito (ver diapositiva 3). Para conseguir esta versión del texto manuscrito, simplemente seguí las instrucciones de revisión de Melville, borrando lo que había marcado para su eliminación e insertando lo que él insertó. Esta versión "limpia” es una representación razonable de las intenciones finales para esta particular versión de su texto.

Revista Iberoamericana, Vol. LXXX, Núm. 246, Enero-Marzo 2014, $31-48$
ISSN 0034-9631 (Impreso) 


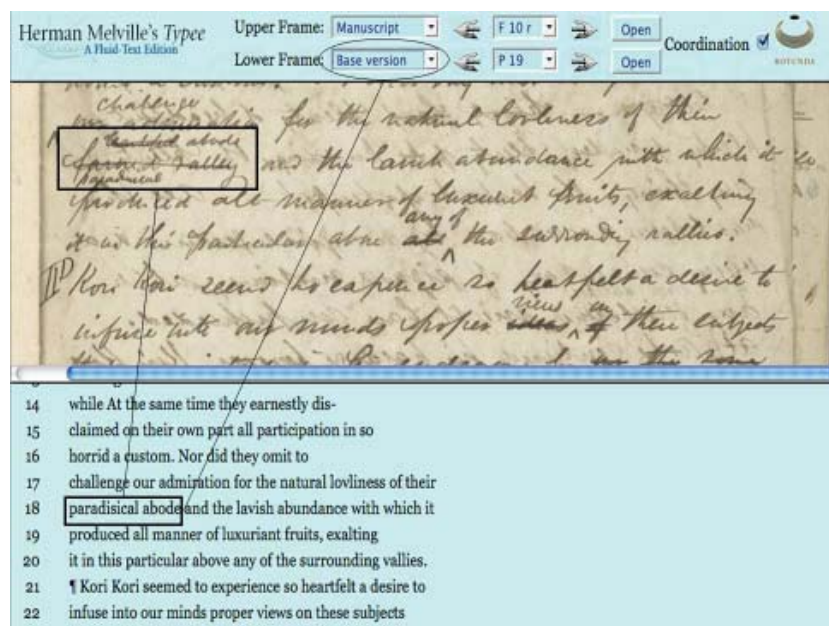

Esta versión de base también puede usarse como un terreno en el cual ubicar los numerosos sitios de revisión del manuscrito (ver diapositiva 4). Aquí, el usuario puede

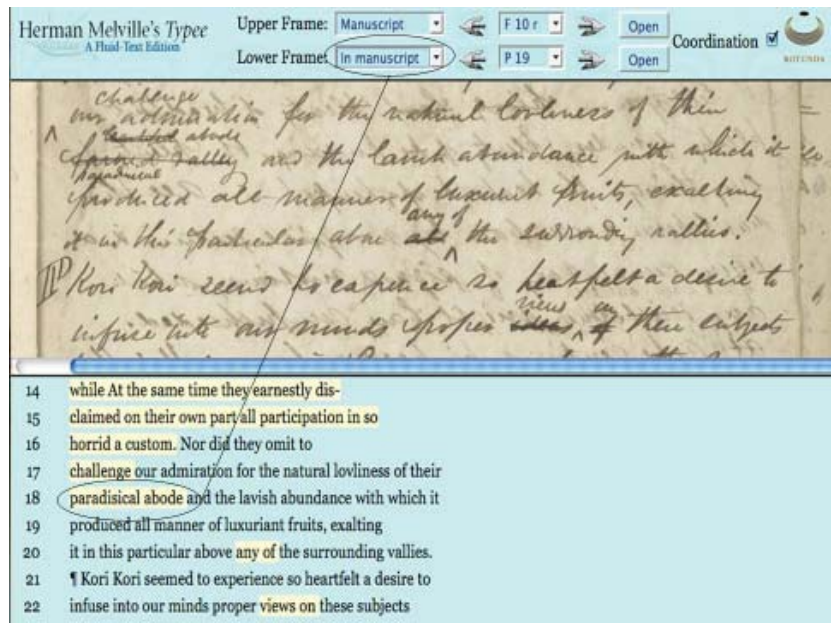

presionar en un vínculo que resalta todos los sitios de revisión. De hecho, los sitios de revisión de Melville están “mapeados” en el terreno textual de la versión de base. Además, cada sitio resaltado es un vínculo que lleva a la secuencia de revisión correspondiente al sitio, sobre lo que volveré más adelante. Pero, para aclarar: el sitio de revisión del que hablaba más arriba aparece en la versión base con las palabras del texto en su revisión

Revista Iberoamericana, Vol. LXXX, Núm. 246, Enero-Marzo 2014, $31-48$
ISSN 2154-4794 (Electrónico) 
final del manuscrito: "paradisíaca morada” (paradisical abode). Cuando las revisiones del manuscrito están resaltadas, paradisical abode se resalta como un sitio de revisión y, cuando un lector presiona en ese vínculo, la secuencia de revisión y la narrativa para ese sitio se abre en una ventana nueva (ver diapositiva 5).

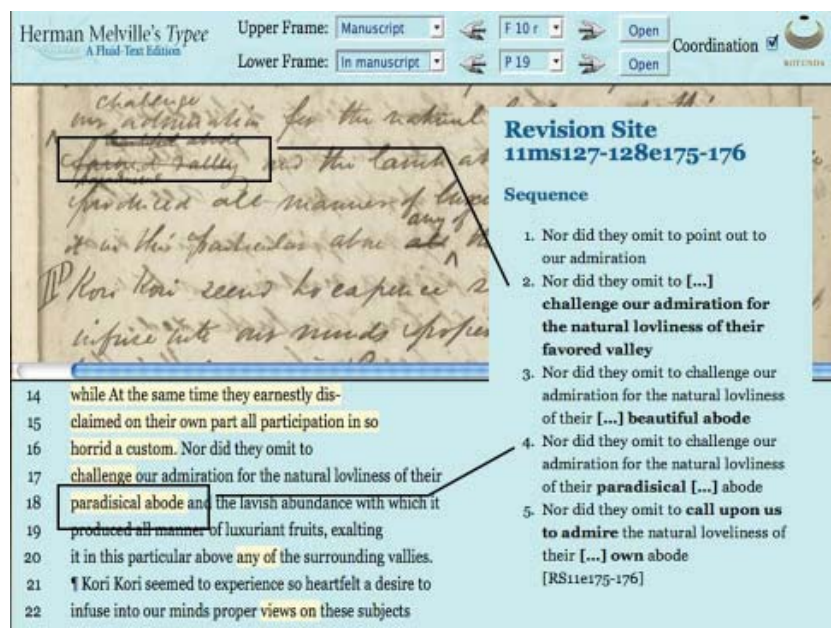

Además de una lista de variantes codificadas (favored, beautiful, paradisical), la Secuencia de Revisión numera cada paso en el proceso de revisión y, lo que es muy importante, ofrece la revisión completa del texto, incluyendo suficiente contexto verbal para hacer legibles el valor, la dirección y el significado de la revisión. Al ofrecer generosos contextos, el lector puede leer más fácilmente las opciones completas que Melville consideró, valorar el impacto de cada supresión o adición y más accesiblemente discernir qué puede haber estado en juego en la estrategia de revisión de Melville.

Siento que estos protocolos del texto fluido empoderan al lector. En primer lugar, desmitifican el estudio del manuscrito al hacer accesibles las imágenes del manuscrito, ampliadas y legibles. En segundo lugar, desmitifican el estudio de la revisión al decodificar códigos de revisión en la hoja del manuscrito y al dar presencia textual a pasos que de otra menera serían invisibles en la secuencia de revisiones.

Por supuesto, cualquier secuencia de revisión es necesariamente hipotética. En tanto que yo veo la secuencia de revisiones de Melville moviéndose de favored a beautiful y a paradisical, otro puede proponer una secuencia alternativa que vaya de favored a paradisical y a beautiful. O se puede estar de acuerdo con mi versión pero por razones diferentes; o se puede conectar mi secuencia con otro sitio de revisión en otro lugar en ésta u otra hoja que muestre que una revisión más adelante en la línea ha motivado esta

Revista Iberoamericana, Vol. LXXX, Núm. 246, Enero-Marzo 2014, $31-48$
ISSN 0034-9631 (Impreso) 
revisión aquí sobre la marcha. La secuencia de revisión es necesariamente debatible y los editores, en mi opinión, están obligados no sólo a editar el debate sino a animarlo y permitirlo. De este modo, recorremos parte del camino para desmitificar el poder editorial. Me gustaría abordar, entonces, dos modos de empoderamiento del lector. El primero es un rasgo final de la edición del texto fluido, que llamo "narrativa de la revisión” ("revision narrative”). El segundo es más futurístico e involucra la edición colaborativa en un campo digital.

La necesidad de una narrativa de la revisión deriva del hecho de que una secuencia de revisión no contiene su propia explicación (ver diapositiva 6). Es una lista, no un

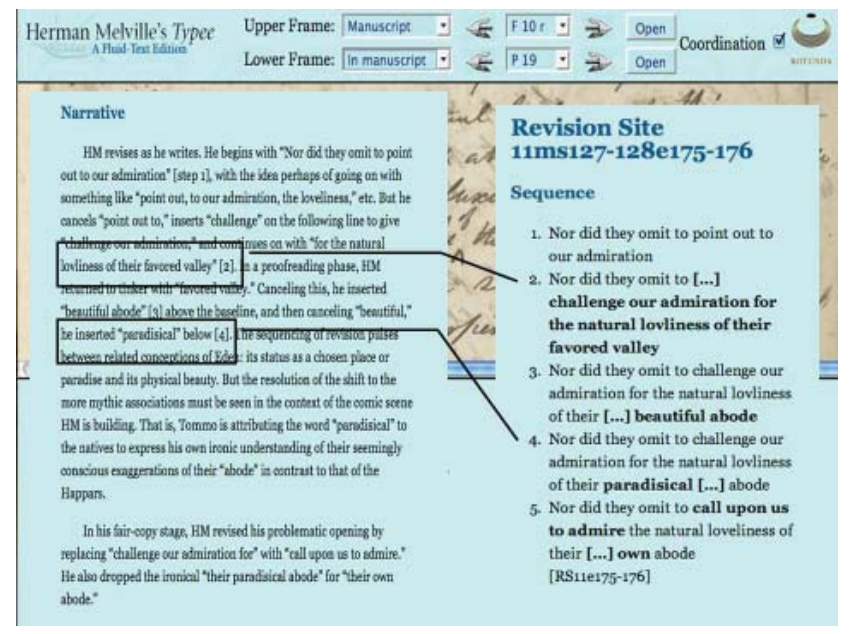

argumento, aunque la lista de pasos sea argumentativa. En efecto, una secuencia no tiene validez hasta que la argumentemos. De este modo, en la edición de Typee, he vinculado cada secuencia a una Narrativa de la Revisión que explica, o que más bien argumenta, qué pasa en cada paso numerado de la secuencia: cuenta la historia de quién escribió qué, cuándo, cómo y por qué. Cada paso numerado en la secuencia de revisión recibe su propia justificación en el correspondiente paso del segmento numerado en la narrativa.

La narrativa de la revisión expone la interpretación inherente a la secuencia de revisión y al exponer la naturaleza hipotética de cualquier intervención editorial, esas narrativas son invitaciones abiertas para hipótesis subsiguientes. Al leer una narrativa de revisión, se anima a los lectores a ejercer sus propios poderes interpretativos -estar o no de acuerdo con la interpretación del editor- y a ofrecer secuencias y narrativas alternativas.

Pero la edición electrónica de Typee es eminentemente estática. El problema es que mientras se puede observar mi comentario crítico en la edición, y sólo el mío, no se

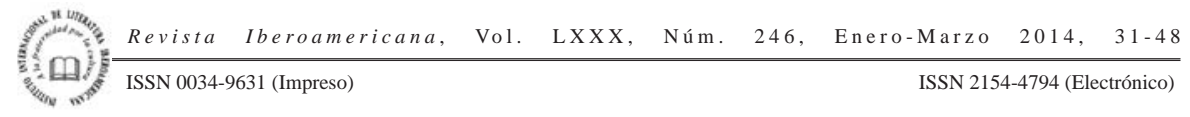


puede usar el sitio digital para agregar cosas a mi trabajo, dialogar con él, debatir con él ni usarlo para reeditarlo o deshacer la edición, ni para generar una revisión alternativa de secuencias y narrativas. En resumen, no permite colaboraciones improvisadas ni interacción del usuario. Lo cual me lleva a una segunda extensión del empoderamiento del lector, quizá más futurista, en el proceso editorial: la edición digital en colaboración.

Desde mi punto de vista, editar es una forma del discurso que combina la historia de los libros y la evolución de los textos. Tal como vengo argumentando, editar no permite trazar las trayectorias de un libro o un texto sin intervención crítica. El terreno convencional para tal discurso han sido los recintos del apenas escrutable aparato textual. Por supuesto, los lectores tienen la libertad de discutir con el aparato, pero eso raramente ocurre, excepto entre otros críticos textuales. La edición digital, sin embargo, expande el terreno de interacción y debate. Nos permite transformar el aparato crítico en un rasgo en colaboración y necesariamente expansible, con un manejo que los estudiantes, críticos literarios y culturales, lectores en general, así como académicos pueden construir y utilizar. Y, al construir una edición del texto fluido, estos colaboradores, a través de su colaboración editorial, dan un paso hacia la desmitificación del proceso editorial. Al construir la Melville Electronic Library, una edición crítica con fondos del NEH, estoy trabajando con colegas y programadores en la Hofstra University y otros lugares, para crear TextLab, una herramienta digital para textos fluidos.

Cuando estéen pleno funcionamiento, TextLab automatizará todos los procedimientos de textos fluidos, permitiendo que los usuarios generen transcripciones diplomáticas, versiones de base y sitios de revisión, secuencias y narrativas. Los usuarios también serán capaces de proponer secuencias y narrativas de revisión alternativas y almacenarlas en la base de datos, junto a aquellas ya creadas y aquellas por venir. Pueden construir la edición en colaboración y con la colaboración del discurso editorial expuesto por completo, lo cual permitirá que los usuarios comprendan los debates editoriales que participan en la confección de una edición crítica.

Como herramienta digital, TextLab permite que los usuarios actúen en dos modos editoriales llamados, de manera poco elegante, “primario” y “secundario”. En la edición primaria (ver diapositiva 7), el usuario sube la imagen de un manuscrito al marco superior (en la versión de prueba de TextLab estamos usando imágenes digitales de hojas del manuscrito del borrador de trabajo de Billy Bud). En un marco inferior, que es un simple editor XML, el usuario transcribe el texto de la hoja, usando una selección de códigos que pone a su disposición el Text Encoding Initiative (Iniciativa de codificación textual). En calidad de persona que transcribe, el rol del editor primario es ofrecer una adecuada traducción de las palabras y los sitios de revisión en cada hoja del manuscrito, codificando supresiones, e inserciones, y vinculándolas con la imagen de la hoja. En la diapositiva 7, vemos que el editor ha transcripto alrededor de una línea de texto sin revisar y que también ha eliminado la palabra "Sailors". Luego, usando la herramienta

\footnotetext{
Revista Iberoamericana, Vol. LXXX, Núm. 246, Enero-Marzo 2014, 31-48 ISSN 0034-9631 (Impreso) ISSN 2154-4794 (Electrónico)
} 


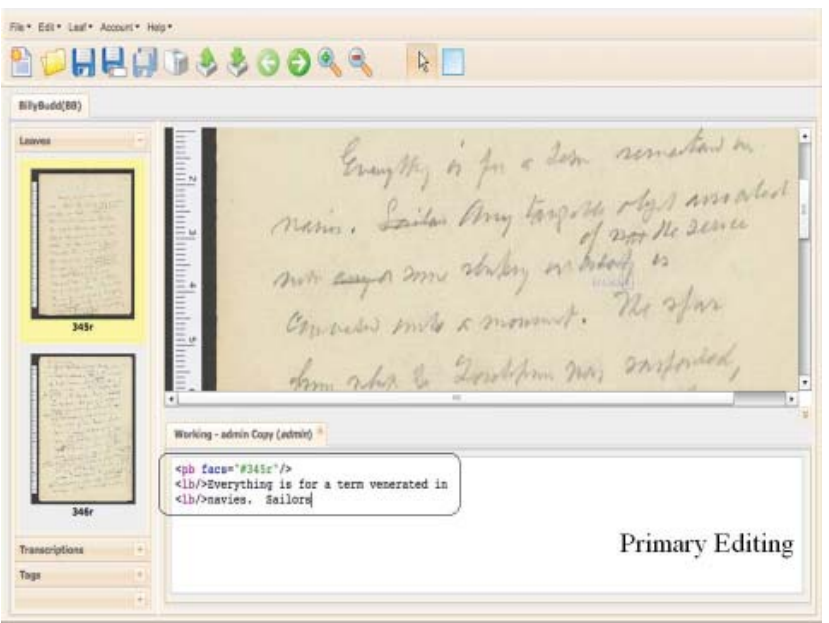

rectangular en la barra de menú, el editor primario coloca un rectángulo alrededor de “Sailors” directamente en la imagen del manuscrito, designando así la palabra eliminada como un sitio de revisión (ver diapositiva 8). Una vez que la palabra “Sailors” también se ha resaltado en el marco inferior de la transcripción, tanto el texto eliminado como el sitio de revisión en la imagen están vinculados, codificados y almacenados en la base

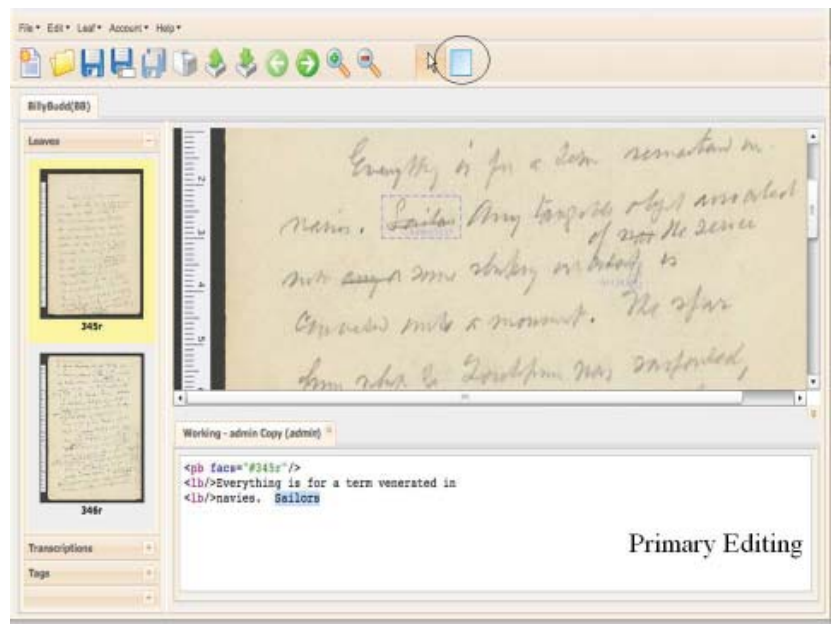

de datos (ver diapositiva 9). El editor primario continúa de esta manera hasta que toda la hoja esté anotada, transcripta y codificada. Una vez que este trabajo de transcripción

\begin{tabular}{l} 
Revista Iberoamericana, Vol. LXXX, Núm. 246, Enero-Marzo 2014, $31-48$ \\
\hline ISSN 0034-9631 (Impreso)
\end{tabular} 


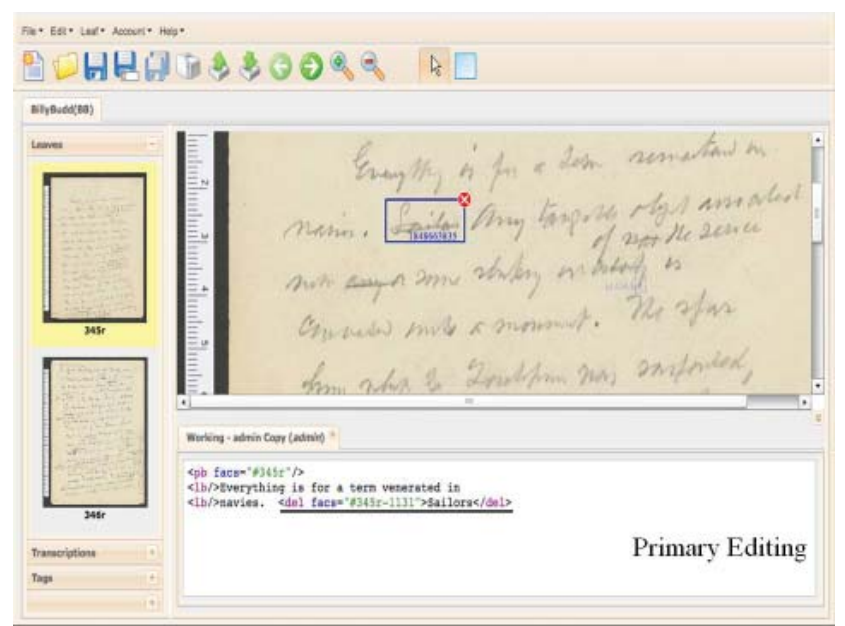

esté examinado por el consejo editorial, se admite la transcripción oficial para el proyecto y se mantiene en la base de datos.

Los rasgos más innovadores de TextLab son las funciones de edición secundaria. Fundamentalmente, el editor secundario trabaja con la transcripción primaria ya existente para elegir un cierto número de sitios de revisión y generar, entonces, una secuencia de revisión y una narrativa de revisión para los sitios colectivos (ver diapositiva 10). El usuario hace doble click en un sitio de revisión en el marco superior y su identificador aparece automáticamente como el primer paso numerado en el cuadro del Sitio, a la

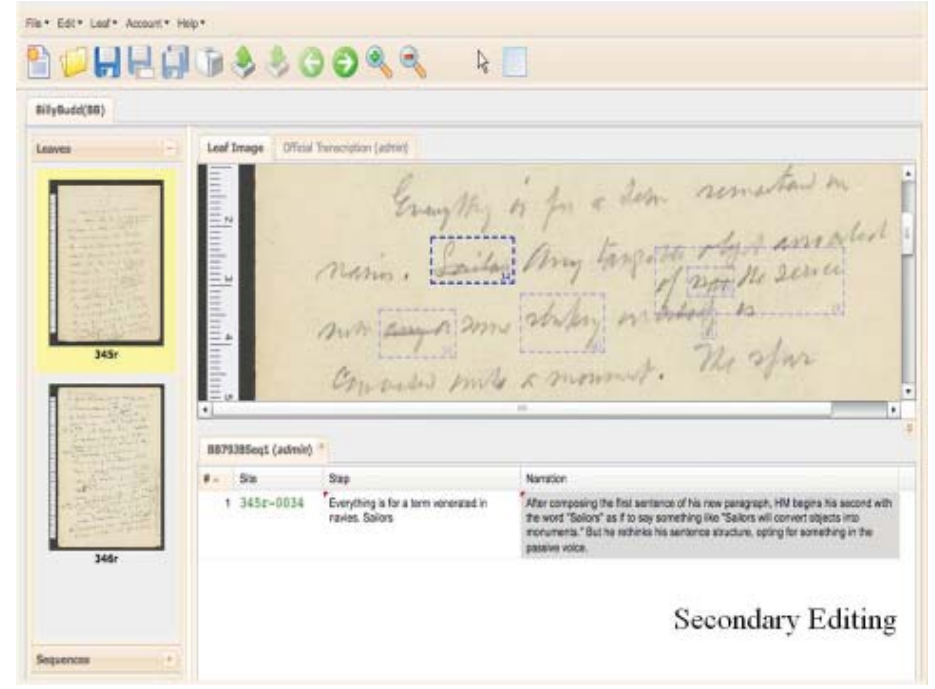

Revista Iberoamericana, Vol. LXXX, Núm. 246, Enero-Marzo 2014, $31-48$
ISSN 0034-9631 (Impreso) 
izquierda, en el editor de la Secuencia de Revisión en el marco inferior. A continuación, el usuario transcribe el texto de revisión del primer paso de la secuencia de revisión en el cuadro del Paso Adyacente y luego compone una narrativa de la revisión en el cuadro de Narrativa a la derecha. El usuario puede continuar agregando más sitios, pasos y narrativas a la secuencia.

En total, TextLab reduce algunos de los aspectos más arduos de la transcripción de manuscritos. Facilita los pasos para anotar la secuencia de revisiones y requiere un argumento en cada paso del camino. Como todo el trabajo está codificado y almacenado, las interpretaciones alternativas de un sitio de revisión pueden compararse fácilmente, promoviendo así tanto la edición en colaboración como el discurso intelectual.

III

Dejando de lado la tecnología digital y a modo de conclusión, quisiera abordar el problema de la traducción no sólo como un modo de revisión sino también como una continuación de la génesis de la obra literaria.

De las formas de "adaptación anunciada” que hemos visto hasta aquí, la traducción debe ser una de las más profundamente transformativas, interpretativas y yo sostendré que genéticas, de los textos fluidos. Le he pedido a Laura López de la Universidad de Barcelona que reuniera para mí traducciones en español y catalán de la frase más conocida de Melville: "Call me Ishmael”. Como es lógico, encontramos casi media docena de opciones, cada una de las cuales ilustra diferentes maneras de interpretar el famoso íncipit, cada una de las cuales evoca la naturaleza de la traducción.

"Llámame Ismael”"

En esta traducción, cada palabra o frase de una obra que da origen en una colocación completamente diferente.

"Llamadme Ismael"

No importa cuánto se aproxime el significado al original. El acto de traducción requiere, tanto en el traductor como en el texto mismo, una mezcla de identidades culturales y textuales; su objetivo aparente es encontrar las palabras que tiendan un puente sobre los huecos que hay entre esas identidades y llegue lo suficientemente cerca como para resumir ciertos matices a pesar de los sacrificios que se operan en ritmo y tono.

"Puedes llamarme Ismael".

Comprendemos completamente que "traducción literal” es imposible, así que la escena de traducción es invariablemente una deconstrucción, un desglose del lenguaje que debe ocurrir cuando dos culturas se encuentran o se mezclan.

"Pongamos que me llamo Ismael".

2 Esta serie de ejemplos está en castellano en el original. $N$ de la $T$.

$\begin{array}{llllll}\text { Revista Iberoamericana, Vol. LXXX, Núm. 246, Enero-Marzo 2014, } & \text { 31-48 } \\ \text { ISSN 0034-9631 (Impreso) }\end{array}$ 
La traducción representa la mutua mezcla de lenguajes pero, al hacerlo, señala así los lazos y las contingencias culturales de la expresión humana.

"Digamos que me llamo Ismael".

Y cuando comparamos el original y la traducción, también extendemos el campo interpretativo de la obra en sí para incluir las intenciones del traductor y el idiolecto de su cultura. En este sentido, la traducción también es una reinvención de la obra que la origina y, por ende, una génesis más.

A modo de experimento, también le pedí a Laura López que tradujera la que probó ser una frase desafiante de Moby-Dick. No me sorprendió en absoluto encontrar traducciones significativamente diferentes en español y catalán.

Tal como “Call me Ishmael”, ésta también aparece en el primer capítulo de Melville. Mientras mira Nueva York y reflexiona sobre cómo los humanos son arrastrados de una manera ineluctablemente narcisista al mar, Ishmael concluye: "But that same image we ourselves see in all rivers and oceans. It is the image of the ungraspable phantom of life; and this is the key to it all”. El problema del traductor es la palabra ungraspable. En inglés, grasp quiere decir tanto aferrarse a algo con urgencia como comprender y por esta combinación de definiciones (material e inmaterial), la palabra ungraspable es una palabra particularmente útil para expresar nuestra incapacidad para tocar y conocer el significado de la vida: la vida es como un fantasma que no podemos asir.

Mi colega llegó a cuatro opciones para ungraspable:

Inalcanzable fantasma de la vida

Inaferrable fantasma

Incomprensible fantasma

Fantasma inabastable

Ninguna de las traducciones al español reúne las connotaciones material e inmaterial que hay en la palabra inglesa ungraspable. "Inalcanzable" a "incomprensible" apelan a lo inmaterial. E "inaferrable” hace referencia a lo concreto. Quizá las tres juntas podrían funcionar. Por otra parte, el catalán “inabastable”, que significa inalcanzable, intocable, que no puede llenarse, llega más cerca y parece una combinación de lo material e inmaterial. Lo que es particularmente interesante aquí es que la palabra "ungraspable” parece en sí misma inasible -o quizá "inabastable"- de modo que el problema de la traducción lleva a la práctica el punto de Melville: ¿este fantasma de la vida? No puedes "atraparlo".

Pero, por supuesto, con la traducción, todo lo que esperamos es un intento de acercarnos y nos preocupamos -creo que innecesariamente- por la fidelidad de la traducción. Invariablemente, pensamos en la traducción como una forma de pérdida; nos preocupa lo que queda "perdido en la traducción”. Pero debemos también ver a la traducción por lo que aporta. Es tanto una revisión como un simulacro. Y es necesariamente una intervención crítica de una cultura sobre otra. La traducción es una versión de la obra literaria que no significa pérdida sino las distancias entre culturas. Sin embargo,

Revista Iberoamericana, Vol. LXXX, Núm. 246, Enero-Marzo 2014, $31-48$
ISSN 0034-9631 (Impreso) 
al mezclar identidades culturales en un solo texto, la traducción nos llama la atención sobre los límites de las identidades textuales de una obra. E, implícita en el acto de la traducción, está nuestra lucha no simplemente por iluminar la distancia cultural, sino también trascender las identidades lingüísticas, textuales y culturales. Finalmente, la traducción es una extensión del texto fluido y, como todas las otras versiones de una obra, es una génesis en sí misma.

La edición de revisiones y de textos fluidos es un tipo de traducción. Es un intento de hacer versiones que sean accesibles y comparables. Es una traducción del texto invisible de la revisión a formas visibles, que son en sí mismas necesariamente debatibles y por ende un asunto del discurso en marcha. En este sentido, editar nunca puede completarse y, como la traducción, sólo puede "acercarse" a transmitir el fenómeno de una obra en desarrollo. Siempre habrá algo perdido en la edición.

Traducción de María Julia Rossi

\section{OBRAS CITADAS}

Bryant, John. The Fluid Text: Editing Revision for Book and Screen. Ann Arbor: U of Michigan P, 2002. ed. Herman Melville's Typee: A Fluid-Text Edition. U of Virginia P. Rotunda Editions. 2006; rev. 2009. Web. 12 October 2008. Melville Unfolding: Politics, Sexuality, and the Versions of Typee. Ann Arbor: U of Michigan P, 2008. "Rewriting Moby-Dick: Politics, Textual Identity, and the Revision. Narrative.” PMLA 125/4 (2010): 1043-60.

"Witness and Access: The Uses of the Fluid Text.” Textual Cultures 2/1 (2007): 16-42.

Gabler, Hans Walter, George Bornstein, and Gillian Borland Pierce, eds. Contemporary German Editorial Theory. Ann Arbor, MI: U of Michigan P, 1995.

Greetham, D. C. Theories of the Text. Nueva York: Oxford UP, 1999.

McGann, Jerome J. A Critique of Modern Textual Criticism. Chicago: U of Chicago P, 1983.

McGann, Jerome J. The Textual Condition. Princeton: Princeton UP, 1991.

McKenzie, D. F. Bibliography and the Sociology of Texts. Londres: British Library, 1986. Shillingsburg, Peter. Scholarly Editing in the Computer Age: Theory and Practice. 1986; $3^{\text {rd }}$ ed., Ann Arbor: U of Michigan P, 1996.

Tanselle, G. Thomas. A Rationale of Textual Criticism. Filadelfia: U of Pennsylvania P, 1989.

“TEI: Text Encoding Initiative.” Text Encoding Initiative Consortium. n.d. Web. 12 October 2008.

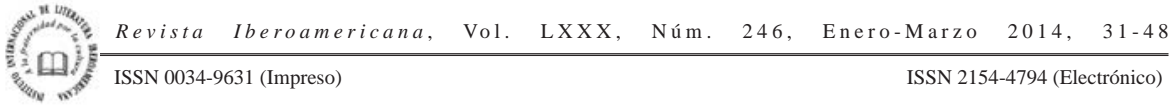


Venuti, Lawrence. The Scandals of Translation: Towards an Ethics of Difference. Londres y Nueva York: Routledge, 1998.

Revista Iberoamericana, Vol. LXXX, Núm. 246, Enero-Marzo 2014, $31-48$
ISSN 0034-9631 (Impreso) 